\title{
The Effect of Paradoxical Tensions between Confucian Culture and Organizational Culture on Fear and Knowledge Sharing Intention
}

\author{
Jinyoung Han \\ Chung-Ang University \\ han1618@cau.ac.kr
}

\author{
Anat Hovav \\ Korea University Business School \\ anatzh@korea.ac.kr
}

\begin{abstract}
Individuals often encounter challenges balancing collaboration and competition in organizational life. Although paradoxes exist in all organizations, there is minimal empirical research investigating paradoxical tensions at the micro level. Furthermore, previous organizational studies have overlooked employees emotionally driven acts. To fill these research gap, this study examined the paradoxical relationships between espoused cultural values, perceived organizational culture, negative emotions (fear of social exclusion), and knowledge sharing in South Korean organizations. The results show that paradoxical tensions between espoused Confucian culture and knowledge sharing supportive culture result in fear of social exclusion. Subsequently, fear of social exclusion has a negative association with knowledge sharing intention. This study contributes to micro-level research of paradoxes by examining the paradoxes of belonging and of performance at the individual level and their influence on employees' knowledge-sharing behavior.
\end{abstract}

\section{Introduction}

Paradoxes exist in all organizations. Paradoxes are defined as concurrent and seemingly mutually exclusive elements [45]. At the individual level, a paradox is a socially, contextually, and culturally constructed phenomenon [46]. That is, while one actor might see two elements as contradictory, another actor might not. Much of the current research on paradoxical tension attempts to understand how organizations and individuals manage dilemmas and paradoxes in various organizational contexts (e.g., [49]). However, there is scant empirical research that aims to understand the cultural and contextual conditions that foster paradoxical tensions at the individual level.
Notwithstanding Keller et al. [37]'s study, which provides an insight to the cultural and organizational conditions that influence individuals' espousal of paradoxical frames. Furthermore, recent papers call for additional empirical studies to better understand the intricacies of cultural backgrounds influence on individuals' construal of paradoxes [42,55].

Early studies emphasized emotions as critical in understanding paradoxes. For example, Huy [34] suggested that paradoxical tensions might result in a negative emotional state such as anxiety and fear. Although Schad et al. [55] called for further research detailing the relationship between negative emotions and individual paradoxical response, to date, there is minimal empirical research that examined the relationships between paradoxical context, negative emotions and employees' behavioral intentions.

Research has suggested that knowledge sharing (KS) among organizational members positively affects organizational performance [17]. However, encouraging knowledge sharing is still problematic as professionals are reluctant to share their knowledge and expertise. KS in organizations is greatly influenced by the cultural values of individuals [28] and by organizational culture [1]. House et al. [27] provides two distinct types of cultural manifestations (i.e., cultural practices and values). Our study focuses on cultural values regarding accepted behavior (shouldbe) rather than cultural practices (as-is).

In Western cultures, KS is a relatively straightforward process driven mostly by a rational decision process and cost-benefit analysis. Withholding information is often considered a "job security" strategy while sharing information in public is used as a tactic to earn reputation, impress superiors and obtain job advancement $[17,50]$.

In Asian cultures (especially ones rooted in Confucian teachings), KS is the product of an implicit emotional dilemma derived from the paradoxical tension between cultural norms and organizational 
culture. This paradox is especially salient in South Korea (hereafter, Korea). Korea is known as the "miracle on the Han river" due to the country's rapid technological and economic development. In the past, Confucian cultural factors such as strong leadership, tendencies to be moderate, interpersonal work relationships emulating a family bond, cooperation, and diligence [66] have been considered as major drivers of these rapid technological developments. However, recently, the Korean government has been calling for the development of a more creative rather than efficiency-driven economy [70].

From organizational task-performance and strategic perspectives, fostering an organizational culture of innovation, teamwork, openness, and trust suggests that KS is likely to benefit the organization (e.g., [1, 40]). On the other hand, from a cultural perspective, maintaining one's place in the group, the dominance of seniors, team harmony, loss of face [39], and low tolerance for mistakes [52] might limit KS among organizational members. For example, organizational members might be reluctant to share knowledge if they feel that they are perceived by their peers as different, or defiant (i.e., knowing more than the project leader) [39]. Specifically, the dilemma between KS supportive organizational culture and the traditional high power distance in Asian cultures could result in what Luscher et al. [45] term as the paradox of performing. The paradox of performing occurs when individuals receive contradictory demands and mixed messages. The dilemma between KS supportive organizational culture and collectivism and Confucian Dynamism (CD) could result in a paradox of belonging [45]. A paradox of belonging exists if an employee belongs to multiple sub-groups with conflicting interests or sub-cultures. A paradox of belonging could also occur when there is a conflict between the individual's social identity (employees) and cultural identity (self-concept).

In this paper, we argue that these dilemmas could manifest themselves in negative emotions (i.e., [34]) such as fear of social exclusion. Given the collective nature of Korean society, fear of social exclusion is a strong emotion and thus fits in the unpleasant-high activation quadrant described by [34]. Such emotion could be paralyzing $[20,34]$ leading to employees' antisocial behavior such as reduced intension to share their knowledge. The goal of this paper is to answer the following research question: How does the paradoxical tension between organizational and national cultures influence fear of social exclusion and $\mathrm{KS}$ in organizations?

This paper is organized as follows. In Section 2, we introduce the theoretical foundations of our research. Sections 3, 4 and 5 describe the research model, hypotheses and research methodology followed by the study's results and analysis. We conclude with a discussion of the results, theoretical and practical implications, suggestions for future research, and a summary.

\section{Theoretical background}

\subsection{Paradox theory}

Paradox is defined as a persistent contradiction between interdependent elements [55] that needs to be managed to achieve positive outcomes [42]. Paradoxical tensions can be contradictory and synergetic concurrently $[10,53,55]$. Paradox has been applied as a meta-theory in management research such as governance [16], change management [20,34], and innovation management [2]. While the contingency approach to management suggests the selection of one "best of breed" solution, paradox theory suggests a middle of the way approach $[2,57]$. This approach is especially applicable to East Asian cultures [37,61].

2.1.1. Individual level. Although limited, studies at the individual level have examined the effect of paradoxical tension on organizational actors' cognition and emotions. Several researchers identified individual cognitive aptitude associated with a greater ability to amalgamate paradoxes. This aptitude has been termed paradoxical thinking and was found to influence creativity $[55,58]$. The main premise of these studies is that while organizational paradoxical tension always exists, individual's perceptions of such tensions depend on their paradoxical frames $[55,58]$ and paradoxical mindset [2]. Individuals use paradoxical frames when they classify a condition by using two opposing categories [37]. Luscher et al. [45] defined 'paradox of performance' as related to mixed messages from the manager to her subordinates and "paradox of belonging' as associated with the interrelatedness of the individual and the group. For example, 'paradox of performance' could occur when a manager verbally promotes self-management and flexibility in problem solving. However, in actuality, the manager expects traditional top-down processes [46]. A paradox of belonging could occur when an individual is deciding, "Should I express myself and risk being wrong OR remain silent and risk not belonging?" [46: p. 231]. Paradoxical tensions can also foster anxiety and uncertainty [46,56], frustration, and fear [34]. Anxiety can promote individuals to apply splitting and projecting defenses, thus construing in- and out-groups [4]. Fiol [20] discusses the dynamics between individual identity and organizational identity in the form of structure and processes. Following Fiol's [23] line of inquiry, we examine the effect of the dynamics between individual identity (i.e., espoused culture) and 
organizational identity (i.e., organizational culture) on employees' behavioral attitude.

2.1.2. Culture and paradox. Using paradoxical frames depends on contextual conditions and the set of beliefs the individual uses to encode these conditions. Thus, individuals' paradoxical frames are often influenced by culture and context [37]. Individuals influenced by East-Asian culture are more likely to adopt paradoxical mindsets than individuals influenced by Western culture. This is because Eastern culture is generally orientated towards embracing contractions [54]. Eastern thinking stresses harmony and "middle of the way" solutions $[10,11]$. That is, Eastern roots apply paradoxical perspectives to explore the nature of existence [55] and highlight contradictions such as light-dark and life-death [10,53]. Eastern narrative also emphasizes that contradictions should be embraced and integrated as the world is constantly changing [53]. Conversely, Western thinking emphasizes contradictions and distinctions [10,12] and "either/or" perspective [53]. Furthermore, traditional western philosophy emphasizes separating paradoxical elements [10,11,19]. Thus, individuals influenced by Eastern philosophy are more likely to engage in simultaneously cooperative and competitive behavior than individuals influenced by Western culture [14,37]. As stated above, paradoxical tension and framing is influenced by context and culture. For example, open organizational culture could help organizations to manage paradoxical tension by achieving ambidexterity [44].

\subsection{Organizational culture}

In this study, we focus on three dimensions of organizational culture that influence $\mathrm{KS}$ in organizations: innovation, fairness, and affiliation. Prior studies suggest the association between innovativeness and KS in organizations. Alavi et al. [1] found that organizational values on innovativeness promoted collaborative use of knowledge management (KM) tools. Innovativeness includes experimenting, flexibility, taking initiative, and risk taking behaviors [9]. Items that are often used to measure innovativeness such as openness and flexibility also facilitate $\mathrm{KS}$ since they encourage interaction among individuals $[1,36]$.

Fair and supportive culture is critical in the context of $\mathrm{KS}$ due to the public goods dilemma. Organizational knowledge could be considered a public good similar to public parks. Since access to organizational knowledge is not limited to the contributors, free-riders might leverage that knowledge without any contribution to its provision [62]. The public goods dilemma suggests that if everyone shares their knowledge and one does not, one can still use the good (i.e., knowledge) with no cost to $\mathrm{him} / \mathrm{her}$. Alternatively, if no one or only a few employees share their knowledge, one is withholding a wasted contribution. Fair and supportive culture builds trust between organizational members and serves to overcome the public goods dilemma associated with KS. Prior research found that supportive, fair, and trusting culture promotes KS within an organization or working group $[3,36]$.

The last dimension is team orientation, which refers to togetherness among an organization's members. An organizational member is considered affiliated if she is collaborative and focuses on team harmony. Affiliation was shown to have a positive association with KS intention [7]. Furthermore, belonging to a team tends to overcome the public goods dilemma by increasing members' tendency to contribute.

Organizational culture could enable or hinder employees' KS intentions [3]. In this study, we focus on KS supportive organizational culture. For the sake of brevity, we will use the term "KS culture" to denote an organizational culture that supports and promotes the sharing of information. Many organizations try to build a KS culture to achieve their business goals and organizational performance. However, we posit that the dilemma between Eastern cultural values or beliefs and $\mathrm{KS}$ culture could lead to paradoxical tension and negative emotions. Subsequent KS intension might vary by employee depending on their paradoxical framing. We suggest that organizational members in Asian cultures have to oscillate between KS culture and espoused culture uneasiness towards excessive KS.

\subsection{Espoused cultural dimensions}

Confucianism was introduced to the Koryo dynasty (918-1392) and was further entrenched in Korea during the Joseon dynasty (1392-1910), which has become the state ideology, a dominant system of beliefs and values about man, society, political legitimacy, and authority [38]. While traditional Confucianism addresses social relationships such as ruler-subject, father-son, husband-wife, elder-younger, and friend-friend [8], it has been extended and used to explain communication in the workplace [41]. For this study, we selected three cultural dimensions to represent Confucian values dominant in Korea (for details, see [30]).

The first dimension is collectivism. We selected ingroup collectivism rather than institutional collectivism [33] since our study investigates the effect of cultural values on fear of exclusion. The level of collectivism (or individualism) of organizational employees represents the affinity of the individual to the group and the degree to which the individual is loyal to the 
group [63]. Members of a collectivist society have cohesive relationships and are more likely to show loyalty to the group [29].

The second dimension is power distance (PD), which is used to a measure the power differential between seniors (선배 in Korean) and juniors (후배 in Korean), or supervisors and subordinates. In low PD environments, employees perceive their supervisors as accessible. In high PD environments, employees perceive their supervisors as inaccessible and "different kind of people" [27:p.46]. The last dimension is common in Asian society and is termed Confucian Dynamism [29]. The ordering relationship espoused by $\mathrm{CD}$ is similar, but not identical, to the one suggested by PD. While ordering is an accepted reality in high PD cultures, it does not imply the existence of respect towards seniors. In contrast, CD implies reverence and respect for seniors $([5,28]$. In addition, individuals with high Confucianism scores are highly sensitive to humility and harmony [30,39]. Organizational members in Asian cultures may feel conflicted between the need to maintain group harmony and one's place in the group and the need to be innovative and creative. The collectivism, PD, and $\mathrm{CD}$ scores for Korea are relatively high compared to other cultures. Every aspect of Korean life is based on a social hierarchy determined by age, years at the company, position in a group, or educational background [51]. As apparent from the above discussion, traditional Asian cultural dimensions might create paradoxical tensions vis-à-vis modern organizational life. This paradox may lead to negative emotions.

\subsection{Negative emotions}

The prevailing bounded rationality paradigm often used in organizational studies to examine decisionmaking, work motivation, leadership, conflict, and negotiation has overlooked employees' subconsciously and emotionally driven acts $[18,23]$. "Emotions and feelings state direct attention to events, thoughts or stimuli, organize perceptual and thought processes, as well as activate and motivate many, if not most, aspects of human behavior [60: p.4]." Although emotions play a critical role in interpersonal behavior [70], they have been overlooked in organizational behavior research [18]. Furthermore, the effect of negative emotions such as fear, guilt, or anxiety on the behavior of employees in the organization has received limited attention [18,21].

The expression of emotions provides the way people interpret and evaluate others' intentions and behavior [18]. When individuals face an unpleasant, high intensity tension, they are likely to become agitated, fearful, or anxious [34]. Furthermore, negative emotions are contextually and culturally dependent. We suggest that the concurrent but seemingly conflicting existence of individual cultural values (i.e., collectivism, $\mathrm{PD}$, and $\mathrm{CD}$ ) and $\mathrm{KS}$ culture (i.e., innovativeness, fairness and affiliation) is likely to influence employees' perceived fear of social exclusion.

Belonging is an inherent need for most people. However, that need is magnified for individuals with high collectivistic scores. The core cultural norms and ideal of collectivist culture is to achieve and promote harmonious interdependence among people [39]. For this study, we selected two types of social exclusion that we deemed relevant to the paradoxical tension created by the espoused Confucian culture in East Asia and perceived organizational KS culture in most organizations in modern Korea: contextual and hierarchical social exclusion. The first social exclusion refers to exclusion of organizational members who do not share knowledge and thus hinder their team's success. We posit that fear of contextual hierarchical exclusion is the result of the "paradox of belonging" [46]. The second hierarchical social exclusion refers to the exclusion of organizational members with strong ties to a supervisor or a manager. We posit that fear of hierarchical exclusion is the result of both the paradox of performance and paradox of belonging [46]. While KS culture supports openness, fairness, and flexibility, the power differentiation common in Asian cultures (PD) demands top-down and strict communication protocols, thus sending mixed messages. Employees with strong ties to their manager might forgo the established protocols and share information regardless of their place in the hierarchy, resulting in social exclusion by their colleagues. Furthermore, employees may feel negative emotions since they cannot share useful information with their manager that may improve organizational performance, nor can they hoard information to maintain harmony with their colleagues.

\section{Research model development}

The extant literature has identified social and cultural attributes of an organization that facilitates KS $[19,48,61]$. In this study, we examine the paradoxical influence of the tension between organizational culture and cultural values on KS. Figure 1 depicts our research model. 


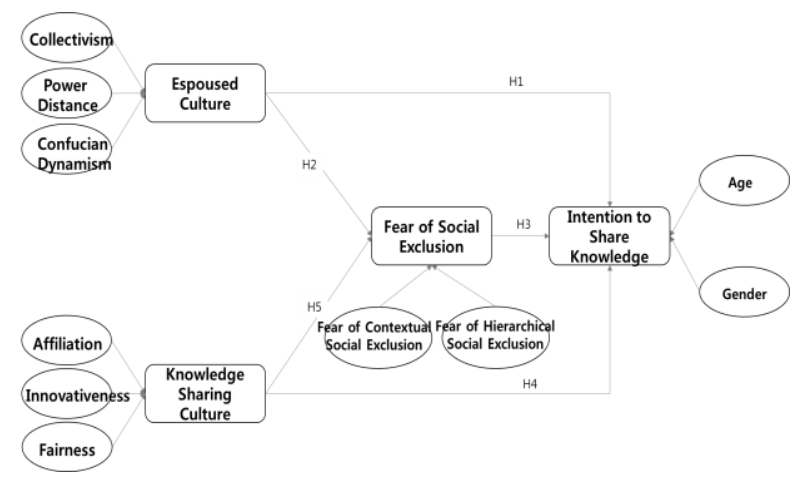

Figure 1. Research Model

Prior research on KS emphasizes the significance of collectivism [65,67]. Collectivistic norms or values positively influence organizational members' willingness to share knowledge within their referent group due to their inclination towards cooperation $[65,67]$. However, the above assertion is rather simplistic and contextual. Collectivistic values combined with Confucian humility create a paradox. While the need to cooperate increases KS intention, group harmony may hinder KS. That is, organizational members may be reluctant to share their knowledge if they feel that they are perceived as different, disturb the " "normal order" [39], or are overly ambitious. Exhibiting superior expertise may hinder unity.

In high PD cultures, the processing of knowledge occurs according to hierarchical order within the organization or team $[28,35]$. Supervisors traditionally have more access to important information and knowledge from external resources than their subordinates [6]. For example, employees with less power in the organization tend to provide information to those with more power. Conversely, people with more power tend to share information with their peers rather than with those in a lower power position [35]. Thus, the direction of knowledge flow is likely to be more restricted in high PD than in low PD cultures. Moreover, seniors in Korean companies expect the use of a special code of conduct to show respect for seniority [41]. For example, forms and contents of greetings and messages vary based on the status of the receiver (colleague versus supervisor) and sender. These restrictions in knowledge flow and expression could cause infrequent communication among team members. Therefore, organizational members who perceive power differences are less likely to share their knowledge.

Ordering relationships by status and observing this order is one of the major characteristics of CD and is based on an unequal status relationship between people [31]. While communication with seniors requires formality [41], which may hinder $\mathrm{KS}$ in high $\mathrm{PD}$ environments, Confucianism suggests that the form of the communication will vary but not the content [41]. Therefore, organizational members with a high $\mathrm{CD}$ score are more likely to share their knowledge with their colleagues regardless of rank. In high CD cultures, long-term relationships with colleagues are also expected [5,23]. Thus, organizational members are likely to share their knowledge to appease others. Given the conflicting effects of espoused culture on $\mathrm{KS}$, we propose that there is no direct positive or negative effect of espoused culture on KS in the Korean context. Hence:

H1: Espoused culture has no association with the intention to share knowledge within an organization.

In this study, we focus on the common negative human emotion of fear. Fear can be seen as a warning signal that a specific desire is associated with a danger or threat. Fear can force an individual to reconsider their decisions or social behavior [24]. For example, a person may postpone quitting her current job in an economic downturn because she is anxious about unemployment. As stated above, paradoxical tension could lead to an emotional state [34]. The propensity to form attachments, and to live and work in groups has a strong evolutionary basis. The fundamental human works and lives in groups because groups enable survival and reproduction [18]. Decreased belongingness may be associated with threats to the individual's wellbeing. The need for social belongingness and fear of social exclusion is likely to be stronger in collectivistic societies. Furthermore, in Confucian culture, the need for harmonious relations with one's referent group is a basic tenet of life $[14,39]$.

In collectivist cultures, being a member of a group is more important than having autonomy [36]. The first step of the Korean culture cycle is to build an emotional bonding community [14]. When two Koreans meet, they typically exchange personal information (e.g., age, hometown, educational background, and hobbies) and try to find some common background [14]. This could be due to the Korean dominant tendency of "in-group harmony." Non-members of the in-group are invisible and often ignored [14]. Conversely, maintaining harmonious relationships with one's in-group is paramount. As stated above, the interplay between collaboration and harmony could cause paradoxical tensions. The need to share knowledge versus the need for harmonious relationships may result in fear of social exclusion (i.e., members who do not share information are excluded from the team. While members who share too much knowledge are seen as pretentious and could also be 
excluded from the team). Thus, individuals in Confucian cultures are more likely to perceive fear of contextual social exclusion.

Furthermore, close relationships with a manager (or senior) are likely to interfere with the social hierarchy common in Asian cultures. Employees who are sensitive to the power differential common in Asian cultures are more likely to be concerned with social exclusion due to their relationships with their managers than are employees with low PD. Thus, we suggest that the espoused culture in Korea is likely to instill fear of hierarchical social exclusion, when the power differential decorum is ignored.

H2: Espoused culture is positively associated with the perceived fear of social exclusion in Korean organizations.

People have an inherent need to belong. The absence of a sense of belonging could threaten an individual's wellbeing. Pro-social behavior within an organization depends on the belief that one is part of a community whose members seeks to aid and support each other [64]. However, when people feel excluded, their inclination to perform pro-social behavior is reduced or possibly eliminated [64]. Furthermore, since fear of social exclusion fits in the unpleasanthigh activation quadrant of the Circumplex model of emotions [40], such emotion could be paralyzing [20, 34], leading employees' to engage in anti-social behavior. Thus, when organizational members fear social exclusion, their inclination would be not to express their opinions or share knowledge [46]. Hence:

H3: Perceived fear of social exclusion is negatively associated with the intention to share knowledge within an organization in Korea.

Previous studies investigated cultural attributes of an organization, which lead to $\mathrm{KS}[1,19,61]$. KS of employees is influenced by organization culture (i.e., a set of shared values or beliefs) since it is a voluntary behavior [1]. Organizational culture of innovativeness stimulates interactions among employees and a disposition toward knowledge sharing as a problemsolving strategy [26]. Organizational culture of fairness promotes KS within an organization or working group by building trust between organizational members [8]. Fairness also helps employees overcome the public goods dilemma (i.e., knowledge) [3]. Organizational culture of affiliation emphasizes collaboration and teamwork and is shown to have a positive association with KS intention [7]. Hence, KS culture positively affects KS intentions of individuals.
H4: KS culture is positively associated with the intention to share knowledge within an organization.

We suggest that when the paradoxical pendulum oscillates towards organizational culture of innovativeness, fairness, and affiliation, individuals are less likely to fear exclusion. For example, organizational fairness suggests that employees' needs are understood and supported. Thus, an employee is less likely to be excluded even if they have strong ties to their manager. Similarly, affiliation suggests that employees are an integral part of the team. Furthermore, innovativeness and flexibility suggest that there is no risk of reprimand if an employee shares erroneous information $[1,36]$. Hence, we hypothesize that:

H5: KS culture is negatively associated with the perceived fear of social exclusion in Korean organizations.

\section{Research method}

The unit of analysis is the individual who works in an organization. Most of the questions are based on previous instruments, while others are newly developed. Existing measures for collectivism [24], power distance [59], Confucian dynamism [5], perceived KS culture [7] and knowledge sharing [7] were adapted and modified based on our research context. We developed new items for the fear of exclusion construct.

We used a convenience sample. We contacted managers within each company and asked the managers to share a list of project members. These members were invited to participate in the study. Respondents were able to participate in the study either by mailing a completed paper questionnaire or by submitting an online version of the survey. A total of 187 respondents returned the questionnaires by e-mail $(32 ; 17.1 \%)$, paper $(82 ; 43.9 \%)$ or online $(73 ; 39.0 \%)$, yielding a response rate of $70.6 \%$. Respondents came from a variety of industries, such as finance $(56.1 \%)$, service $(10.7 \%)$, construction $(9.6 \%)$, government $(7.5 \%)$, retail $(4.8 \%)$, manufacturing $(4.3 \%)$, and other industries $(6.9 \%)$.

\section{Data analysis and results}

\subsection{Analysis method}

Partial least squares (PLS) regression was chosen to examine the proposed model for the following reasons. First, PLS is suitable for assessing theories in the early stages of development. Second, compared to other SEM (structural equation modeling) techniques, PLS 
requires minimal demands on sample size in order to validate a model [13]. These two reasons assure the appropriateness of PLS for testing the proposed model using the gathered data. This study used SPSS 23.0 and WarpPLS5.0 to analyze the measurement and structural models.

\subsection{Measurement model}

Content validity of the instrument was established by ensuring that the measurement items are consistent with the extant literature, pre-testing the instrument and receiving guidance from a panel of experts. Convergent validity was assessed by extracting composite reliability and the average variance value (AVE) [25]. Table 1 shows that the composite reliability values for all constructs are larger than 0.5 . These demonstrate appropriate reliability and convergent validity for all measures. Finally, the discriminant validity of the instrument was verified by examining the square root of the AVE [22].

Table 1. Quality of the constructs

\begin{tabular}{|c|c|c|c|c|c|c|}
\hline & $\begin{array}{c}\text { No. of } \\
\text { items }\end{array}$ & Mean & $\begin{array}{c}\text { Standard } \\
\text { Deviation }\end{array}$ & AVE & $\begin{array}{c}\text { Composite } \\
\text { Reliability }\end{array}$ & $\begin{array}{c}\text { Cronbach's } \\
\text { Alpha }\end{array}$ \\
\hline IntKS & 5 & 5.578 & 1.097 & 0.826 & 0.959 & 0.947 \\
\hline FearSE_H & 4 & 2.100 & 1.261 & 0.846 & 0.956 & 0.939 \\
\hline FearSE_C & 4 & 2.468 & 1.412 & 0.736 & 0.918 & 0.881 \\
\hline Affi & 4 & 5.151 & 1.200 & 0.873 & 0.965 & 0.952 \\
\hline Inn & 4 & 4.908 & 0.047 & 0.806 & 0.943 & 0.920 \\
\hline Fair & 3 & 4.959 & 1.176 & 0.785 & 0.917 & 0.863 \\
\hline Coll & 4 & 4.413 & 1.337 & 0.547 & 0.827 & 0.722 \\
\hline PDI & 3 & 3.734 & 1.536 & 0.585 & 0.808 & 0.644 \\
\hline CD & 4 & 4.493 & 1.229 & 0.677 & 0.893 & 0.839 \\
\hline
\end{tabular}

IntKS: Intention to share knowledge, FearSE_C: Fear of contextual social exclusion, FearSE H: Fear of hierarchical social exclusion, Affi: Affiliation, Inn: Innovation, Fair: Fairness, Coll: Collectivism, PDI: Power distance index, CD: Confucian Dynamism

Table 2 shows that the square root of the AVE for each construct was larger than the correlations between the average variance and all the other constructs. Furthermore, the results of the inter-construct correlations showed that each construct shared greater variance with its own measures than with other measures.

Table 2. Correlations between first-order constructs

\begin{tabular}{|c|c|c|c|c|c|c|c|c|c|}
\hline & 1 & 2 & 3 & 4 & 5 & 6 & 7 & 8 & 9 \\
\hline 1 & 0.909 & & & & & & & & \\
\hline 2 & -0.366 & $\mathbf{0 . 9 2 0}$ & & & & & & & \\
\hline 3 & -0.187 & 0.670 & $\mathbf{0 . 8 5 8}$ & & & & & & \\
\hline 4 & 0.316 & -0.095 & -0.047 & $\mathbf{0 . 7 3 9}$ & & & & & \\
\hline 5 & 0.102 & 0.192 & 0.242 & 0.215 & $\mathbf{0 . 8 2 3}$ & & & & \\
\hline 6 & -0.110 & 0.376 & 0.345 & 0.177 & 0.350 & $\mathbf{0 . 7 6 5}$ & & & \\
\hline 7 & 0.504 & -0.357 & -0.218 & 0.361 & -0.012 & 0.017 & $\mathbf{0 . 9 3 5}$ & & \\
\hline 8 & 0.405 & -0.308 & -0.120 & 0.315 & 0.192 & -0.001 & 0.606 & 0.886 & \\
\hline 9 & 0.458 & -0.244 & -0.145 & 0.369 & 0.088 & 0.100 & 0.806 & 0.570 & 0.898 \\
\hline
\end{tabular}

* 1: Intention to share knowledge, 2: Fear of hierarchical social exclusion, 3 : Fear of contextual social exclusion, 4: Collectivism, 5: Confucian Dynamism, 6:

Power distance index, 7: Affiliation, 8: Fairness, 9: Innovativeness

${ }^{\star *}$ The bold numbers on the diagonal are the square roots

\subsection{Structural model}

Figure 2 shows the analysis results of the model with path coefficients, $\mathrm{p}$-values of the paths, and Rsquare value. Significance tests for all the paths in the model were conducted using a bootstrap resampling procedure. Among the five hypothesized paths, four are found to be significant at the level of 0.01 . Fear of social exclusion is negatively related to the intention to share knowledge $(\beta=-0.20 ; \mathrm{p}<0.01)$ and $\mathrm{KS}$ culture is positively related to the intention to share knowledge $(\beta=0.43 ; \mathrm{p}<0.01)$ as expected. Paradoxical tension between espoused culture and organizational culture is shown in the form of fear of social exclusion. The relationship between espoused culture and fear of social exclusion is positive $(\beta=0.37 ; p<0.01)$ while the relationship between organizational culture and fear of social exclusion is negative $(\beta=-0.36 ; p<0.01)$. Therefore, hypotheses H1, H2, H3, H4, and H5 are supported.

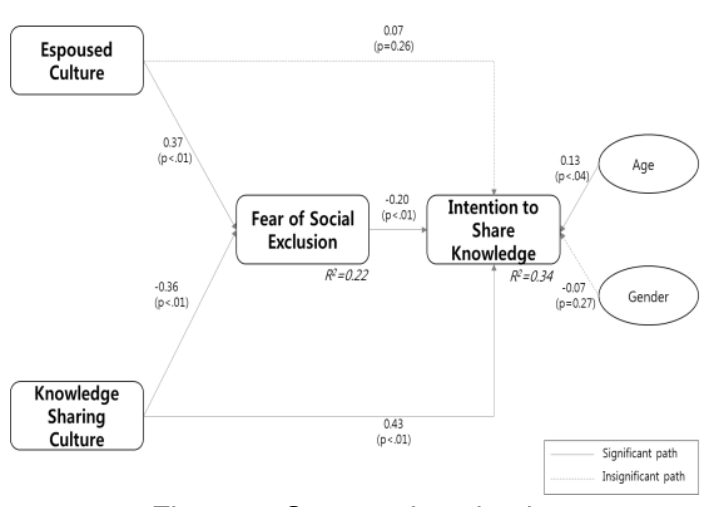

Figure 2. Structural evaluation

\section{Discussion and implications}

\subsection{Discussion}

Applying paradoxical lens at the individual level, we have examined a current gap in our understanding of how contradictory cultures negatively influences individuals and how these negative emotions (fear) influence employees' pro-social behavior (i.e., knowledge-sharing). Paradox at the individual level is socially and contextually constructed [51]. Yet, despite recent calls by [42] and Schad et al. [65], there is limited empirical research that aims to understand the cultural and contextual conditions that foster paradoxical tensions at the individual level (notwithstanding [41]). Similarly, current research agrees that paradoxical tensions can result in negative emotions such as fear, anxiety, or anger (e.g., [34]), and has called for a better understanding of the 
relationships between these emotions and individuals' responses.

In this study, we use paradoxical lens to empirically measure the influence of the tension created by balancing organizational and espoused culture on employees' fear of social exclusion and subsequent intention to share knowledge in Korea. We chose Korea as an example since the traditional Confucian culture is in conflict with post-modern organizational culture.

As expected, organizational culture of fairness, innovativeness and affiliation increases KS intention. As argued, the traditional Confucian culture had no significant effect on KS intensions. This is because Confucian culture is often contextual where sharing information is situational and informal. Our results also suggest that while organizational culture reduces fear of social exclusion, espoused Asian culture increases fear of social exclusion in the context of KS. Furthermore, fear of social exclusion significantly reduces KS intention. These results suggest that employees face a dilemma and thus oscillate between the two cultures. If the pendulum leans towards organizational culture of fairness, innovation and affiliation, employees' fear of social exclusion is lower and they are more likely to share their knowledge. If the pendulum leans towards Asian espoused culture, employees fear of social exclusion increases and they are less likely to share their knowledge.

Previous knowledge sharing studies at the individual level focused on individual traits or organizational culture as antecedents of KS (e.g., [47]). In the enhanced study of [68], a synthesized conceptual model is provided incorporating organizational, contextual, motivational, and individual factors as predecessors of KS intentions. However, Wang and Noe [68]'s model disregards the inherent interrelationships between contextual and individual factors. Understanding the interaction of these factors and their effects on individuals' intentions and behavior is gaining importance in the complexity of real business context. This study address this gap by highlighting the contradictory effects of interrelationships between individual factors (i.e., cultural norms) and organizational factors (i.e., espoused culture) on employees' prosocial behavior by applying paradoxical lens. While the concepts of paradoxical synthesis and ambidexterity are touted as ways to manage paradoxical tensions at the organizational level, implementing these concepts at the individual level is more difficult. Rather, we suggest that our model supports the idea that people "improvise" [15] depending on contextual circumstances. Practically, employing paradoxical lens may enlighten practitioners in understanding employee's prosocial behavior. Organizational culture emphasizing innovation and affiliation is conducive to knowledge sharing. It appears that the importance of organizational culture lies in its ability to have a direct effect on employees' knowledge sharing behavior. An important caveat is that the effects of KS supportive culture on knowledge sharing could be hindered by espoused cultural values of employees.

\subsection{Limitations and future Research}

This study has several limitations, which provide future research directions. First, this study was conducted in Korea and thus has limited generalizability. Future research could examine our research question in other cultures. Second, this study investigated only fear of social exclusion as results of paradoxical tensions between espoused cultures and KS supportive cultures. Future research can examine other negative emotions such as anxiety or frustration. Furthermore, Eastern specific emotions like fear of losing face can also be examined in future research. This study is limited, like other cross-sectional studies, in attributing and validating causality. Future studies could expand our understanding of paradoxes using a process lens with longitudinal approach that explores the proposed dynamics over time and assess causal relationships.

\section{Conclusions}

By adopting paradox as a theoretical lens, this study provides a better understanding of the paradoxical tensions between Confucian culture and knowledge supportive organizational culture and their effects on prosocial behavioral intentions of employees. Organizational culture of innovativeness, fairness and affiliation reduces fear of social exclusion and improves prosocial behavior in the form of $\mathrm{KS}$ intention. Conversely, espoused culture in an Asian context reduces prosocial behavior via fear of social exclusion. We conceptualize fear of social exclusion as the outcome of the paradoxical tensions between Confucian culture and KS culture. Since fear of social exclusion reduces prosocial behavior, managers should foster KS supportive culture. When employees oscillate towards organizational culture of innovation, fairness and affiliation, they are more likely to overcome their fear of social exclusion and thus share knowledge.

\section{References}

[1] M. Alavi, T. R. Kayworth, and D. E. Leidner, "An empirical examination of the influence of organizational culture on 
knowledge management practices," Journal of Management Information Systems, 2005, pp.191-224.

[2] C. Andriopoulos, and M. W. Lewis, "Managing innovation paradoxes: Ambidexterity lessons from leading product design companies," Long Range Planning, 2010, pp.104-122.

[3] A. Ardichvili, "Learning and knowledge sharing in virtual communities of practice: Motivators, barriers, and enablers," Advances in Developing Human Resources, 2008, 541-554.

[4] B. E. Ashforth and P. H. Reingen, "Functions of dysfunction: Managing the dynamics of an organizational duality in a natural food cooperative," Administrative Science Quarterly, 2014, pp.474-516.

[5] W. O. Bearden, R. B. Money, and J. L. Nevins, "A Measure of Long-Term Orientation: Development and Validation," Journal of the Academy of Marketing Science, 2006, pp.456467.

[6] R. S. Bhagat, B. L. Kedia, P. D. Harveston, and H. C. Triandis, "Cultural Variations in the Cross-Border Transfer of Organizational Knowledge: An Integrative Framework," Academy of Management Review, 2002, 204-221.

[7] G. Bock, R. Zmud, Y. Kim, and J. Lee, "Behavioral Intention Formation in Knowledge Sharing: Examining the Roles of Extrinsic Motivators, Social-Psychological Forces, and Organizational Climate," Management Information Systems Quarterly, 2005, pp.87-111.

[8] D. Carl, V. Gupta, and M. Javidan, Power Distance. SAGE Publications, New Delhi, London, 2004.

[9] J. A. Chatman, and K. A. Jehn, "Assessing the relationship between industry characteristics and organizational culture: how different can you be?" Academy of Management Journal, 1994, pp.522-553.

[10] M. J. Chen, "Transcending paradox: The Chinese "middle way" perspective," Asia Pacific Journal of Management, 2002, pp.179-199.

[11] M. J. Chen, "Reconceptualizing the competitioncooperation relationship: A transparadox perspective," Journal of Management Inquiry, 2008, pp.288-304.

[12] M. J. Chen and D. Miller, "The relational perspective as a business mindset: Managerial implications for East and West," Academy of Management Perspectives, 2011, pp.6-18.

[13] W. Chin, B. Marcolin, and P. Newsted, "A Partial Least Squares Latent Variable Modeling Approach for Measuring Interaction Effects: Results from a Monte Carlo Simulation Study and an Electronic-Mail Emotion/Adoption Study," Information Systems Research, 2003, pp.189-217.

[14] Y. H. Cho and J. Yoon, "The Origin and Function of Dynamic Collectivism: An Analysis of Korean Corporate Culture," Asia Pacific Business Review, 2001, pp.70-88.

[15] S. R. Clegg, J. V. Cuhna, and M. P. Cuhna, "Management paradoxes: A relational view," Human Relations, 2002, pp.483503.

[16] C. M. Daily, D. R. Dalton, and A. A. Cannella, "Corporate governance: Decades of dialogue and data," Academy of Management Review, 2003, 371-382.

[17] T. H. Davenport and L. Prusak, Working Knowledge: How Organizations Manage What They Know. Harvard Business Press, Boston, 2000.

[18] C. K. W. D. Dreu, M. A. West, A. H. Fischer, and S. MacCurtain, Origins and Consequences of Emotions in Organizational Teams. John Wiley \& Sons, 2001.
[19] T. Fang, "Yin Yang: A new perspective on culture," Management and Organization Review, 2012, pp.25-50.

[20] C. M. Fiol, "Capitalizing on paradox: The role of language in transforming organizational identities," Organization Science, 2002, pp.653-666.

[21] H. Flam, Fear, Loyalty and Greedy Organizations, in Emotion in Organizations, S. Fineman (ed.). Sage Publications Ltd, 2000.

[22] C. Fornell and D. Larcker, "Evaluating Structural Equation Models with Unobservable Variables and Measurement Error," Journal of Marketing Research, 1981, pp.39-50.

[23] D. E. Gibson, "Emotional Episodes at Work: An Experiential Exercise in Feeling and Expressing Emotions," Journal of Management Education, 2006, pp.477-500.

[24] W. B. Gudykunst and C. M. Lee, "Assessing the Validity of Self Construal Scales," Human Communication Research, 2003, pp.253-274.

[25] J. Hair Jr, R. Anderson, R. Tatham, and W. Black, ,Multivariate Data Analysis: With Readings. Prentice-Hall, Inc. Upper Saddle River, NJ, USA,1995

[26] M. Hoegl, K. P. Parboteeah, and H. G. Gemuenden, "When teamwork really matters: task innovativeness as a moderator of the teamwork-performance relationship in software development projects," Journal of Engineering and Technology Management, 2003, pp.281-302.

[27] G. Hofstede, "Motivation, Leadership, and Organization: Do American Theories Apply Abroad?," Organizational Dynamics, 1980, pp.42-63.

[28] G. Hofstede, Culture's Consequences: Comparing Values Behaviors, Institutions, and Organizations across Nations, Sage Publications, Inc., Thousand Oaks, CA, 2001.

[29] G. Hofstede \& M.Bond, "The Confucius Connection: From Cultural Roots to Economic Growth," Organizational Dynamics, 1988, pp.5-21.

[30] G. Hofstede and R. McCrae, "Personality and Culture Revisited: Linking Traits and Dimensions of Culture," CrossCultural Research, 2004, pp.52-88.

[31] G. H. Hofstede, G. J. Hofstede, and M. Minkov, Cultures and Organizations: Software of the Mind: Intercultural Cooperation and Its Importance for Survival. McGraw-Hill Professional, 2010.

[32] R. J. House, P. J. Hanges, M. Javidan, M., P. W. Dorfman, V. Gupta, Culture, Leadership, and Organizations: The GLOBE Study of 62 Societies. Sage: Thousand Oaks, CA. 2004.

[33] R. J. House, N. R. Quigley, \& M. S. De Luque, "Insights from Project GLOBE," International Journal of Advertising, 2010, 111-139.

[34] Q. N. Huy, "Emotional balancing of organizational continuity and radical change: The contribution of middle managers," Administrative Science Quarterly, 2002, pp.31-69.

[35] M. Ipe, "Knowledge Sharing in Organizations: A Conceptual Framework," Human Resource Development Review, 2003, pp.337-359.

[36] T. Jacks, S. Wallace, and H. Nemati, "Impact of Culture on Knowledge Management: A meta-analysis and framework," Journal of Global Information Technology Management, 2012, pp. $8-42$.

[37] J. Keller, J. Loewenstein, and J. Yan, "Culture, conditions and paradoxical frames," Organization Studies, 2017, pp.539560 . 
[38] Y. W. Kihl, "The Legacy of Confucian Culture and Southe Korean Politics and Economics: An Interpretation," Young, 1994, pp.37-53.

[39] J. Y. Kim and S. H. Nam, "The Concept and Dynamics of Face: Implications for Organizational Behavior in Asia," Organization Science, 1998, pp.522-534.

[40] R. J. Larsen and E. E. Diener, Promises and problems with the circumplex model of emotion. In M. S. Clark (ed.), Review of Personality and Social Psychology: Emotion and Social Behavior, 114: 25-59, CA: Sage, 1992.

[41] O. Lee, "The Role of Cultural Protocol in Media Choice in a Confucian virtual Workplace," IEEE Transactions on Professional Communication, 2000, pp.196-200.

[42] M. W. Lewis, "Exploring paradox: Toward a more comprehensive guide," Academy of Management Review, 2000, pp.760-776.

[43] P. P. Li, "The Unique Value of Yin- Yang Balancing: A Critical Response," Management and Organization Review, 2014a, pp.321-332.

[44] H. -E. Lin, E. F. McDonough, S. J. Lin, and C. Y. Y. Lin, "Managing the Exploitation/Exploration Paradox: The Role of a Learning Capability and Innovation Ambidexterity," Journal of Product Innovation Management, 2013, pp.262-278

[45] L. S. Luscher, M. Lewis, and A. Ingram, "The social construction of organizational change paradoxes," Journal of Organizational Change Management, 2006, pp.491-502.

[46] L. S. Luscher and M. W. Lewis, "Organizational change and managerial sensemaking: Working through paradox," Academy of Management Journal, 2008, pp.221-240.

[47] K. Matzler and J. Mueller, "Antecedents of knowledge sharing-Examining the influence of learning and performance orientation," Journal of Economic Psychology, 2011, pp.317329.

[48] R. McDermott and C. O'Dell, "Overcoming cultural barriers to sharing knowledge," Journal of Knowledge Management, 2001, 76- 85 .

[49] E. Miron-Spektor, F. Gino, and L. Argote, "Paradoxical frames and creative sparks: Enhancing individual creativity through conflict and integration," Organizational Behavior and Human Decision Processes, 2011, pp.229-240.

[50] R. M. Muller, M. Spiliopoulou, and H. J. Lenz, "The Influence of Incentives and Culture on Knowledge Sharing," Proceedings of the 38th Hawaii International Conference on System Sciences: IEEE Computer Society, 2005, pp. 247b.

[51] H. Park, J. Blenkinsopp, M. K. Oktem, and U. Omurgonulsen, "Cultural Orientation and Attitudes toward Different Forms of Whistleblowing: A Comparison of South Korea, Turkey, and the UK," Journal of Business Ethics, 2008, 929-939.

[52] M. Park and M. Kim, "Communication Practices in Korea," Communication Quarterly, 1992, pp.398-404.

[53] R. Payne and C. L. Cooper, Emotions at Work: Theory, Research, and Applications in Management. Chichester, UK: Wiley, 2001.
[54] K. Peng and R. E. Nisbett,"Culture, dialectics, and reasoning about contradiction," American Psychologist, 1999, pp.741-754.

[55] K. Peng, J. Spencer-Rodgers, and N. Zhong, Naïve dialecticism and the Tao of Chinese thought. In U. Kim, G. Yang, \& K.-K. Hwang (Eds.), Indigenous and cultural psychology: Understanding people in context (pp. 247262). Springer, New York, 2006.

[56] J. Schad, M .W. Lewis, S.Raisch, \& W.K.Smith, "Paradox research in management science: Looking back to move forward," Academy of Management Annals, 2016, pp.5-64.

[57] K. J. Schneider, The paradoxical self: Toward an understanding of our contradictory nature. Prometheus Books, 1990.

[58] W. K. Smith and M. W. Lewis, "Toward a theory of paradox: A dynamic equilibrium model of organizing," Academy of Management Review, 2011, pp.381-403.

[59] W. K. Smith and M. L. Tushman, "Managing strategic contradictions: A top management model for managing innovation streams," Organization Science, 2005, pp.522-536.

[60] M. Srite and E. Karahanna, "The Role of Espoused National Cultural Values in Technology Acceptance," Management Information Systems Quarterly, 2006, pp.679-704.

[61] R. O. Stanley and G. D. Burrows, Varieties and Functions of Human Emotion. Wiley Chichester, UK, 2001.

[62] V. Suppiah and M. Singh Sandhu, "Organisational culture's influence on tacit knowledge-sharing behaviour," Journal of Knowledge Management, 2011, pp.462-477.

[63] J. W. Sweeney Jr, "An experimental investigation of the free-rider problem. Social Science Research,” 1973, pp.277-292. [64] H. C. Triandis and M. J. Gelfand, "Converging Measurement of Horizontal and Vertical Individualism and Collectivism," Journal of Personality and Social Psychology, 1998, pp.118-128.

[65] J. M. Twenge, R. F. Baumeister, C.N. DeWall, N.J.Ciarocco, and J.M.Bartels, "Social Exclusion Decreases Prosocial Behavior," Journal of Personality and Social Psychology, 2007, pp.56-66.

[66] B. van den Hooff and J. Ridder, "Knowledge Sharing in Context: The Influence of Organizational Commitment, Communication Climate and CMC Use on Knowledge Sharing," Journal of Knowledge Management, 2004, pp.117-130.

[67] E. Vogel, Japan as Number One: Lessons for America. Cambridge Harvard University Press, 1979.

[68] J. A. Wagner III, "Studies of Individualism-Collectivism: Effects on Cooperation in Groups," Academy of Management Journal, 1995, pp.152-172.

[69] S. Wang, and R. A. Noe, "Knowledge sharing: A review and directions for future research," Human Resource Management Review, 2010, pp.115-131.

[70] S. K. Hwang, Creative economy and job creation: Focusing on creative employment, KDI policy study, 2014. 